\title{
Magnetite Nanoparticles Encapsulated with PCL and Poloxamer by Nano Spray Drying Technique
}

\author{
Caio Perecin ${ }^{1,2, *}$, Natalia Cerize ${ }^{2, *}$, Valmir Chitta ${ }^{3}$, Xavier Gratens ${ }^{3}$, \\ Patricia Léo $^{2}$, Adriano de Oliveira ${ }^{2}$, Sergio Yoshioka ${ }^{1}$ \\ ${ }^{1}$ Bioengineering Program, University of São Paulo, São Carlos, SP, Brazil \\ ${ }^{2}$ Bionanomanufacturing Center, Institute for Technological Research, São Paulo, SP, Brazil \\ ${ }^{3}$ Institute of Physics, University of São Paulo, São Paulo, SP, Brazil
}

\begin{abstract}
Polymeric particles loaded with biocompatible magnetic nanoparticles are promising platforms to perform therapy and diagnostic of diseases, acting as the so called theranostic agents. In this work, magnetite nanoparticles were synthesized by coprecipitation method and encapsulated with Polycaprolactone (PCL) and Poloxamer 188 polymers through the innovative Nano Spray Drying technique. X-Ray Diffraction and Infrared Spectroscopy confirmed that the formed particles are composed by PCL, Poloxamer and magnetite, with amount of magnetite determined as 3\% by Thermogravimetric Analysis. Particles present a superparamagnetic-like behaviour at $300 \mathrm{~K}$, having negligible coercivity. Dynamic Light Scattering and Scanning Electron Microscopy indicated that the hydrodynamic diameters are of $49 \mathrm{~nm}$ for magnetite nanoparticles and of approximately $600 \mathrm{~nm}$ for encapsulated particles, with aspect analogous to a "nanocookie" of a PCL/Poloxamer blend with magnetite nanoparticles embedded in it. Cytotoxicity assays presented IC 50 superior to 2.5 $\mathrm{mg} / \mathrm{mL}$ for healthy cells and a higher viability of cancer cells in comparison to control, suggesting that the particles may have affinity for tumours, which can be useful for the intended biological applications.
\end{abstract}

Keywords Theranostics, Magnetite, Nano Spray Drying, PCL, Poloxamer 188, Nanoparticles

\section{Introduction}

Iron oxide nanoparticles, such as magnetite and maghemite, present adequate biocompatibility and magnetic properties for therapeutic and diagnostic applications, including magnetic hyperthermia [1], magnetic drug-delivery [2] and magnetic resonance imaging [3], which characterize them as theranostic agents [4]. However, pure iron oxide is not stable in aqueous media and tend to be oxidized by air, so it is crucial to create manners to stabilize them [5]. Polymer encapsulation can fulfill this need and provide other advantages, depending on polymers used.

The polymers used for encapsulation must be chosen accordingly to the application. For cancer treatment, particles should have good bioavailability and be able to cross the biological barriers. Polymer blends of Polycaprolactone (PCL) and Poloxamer 188 have shown good potential for these porpouses, allowing efficient drug-delivery and controlled release of the encapsulated content [6], and both have been tested separetedely in

* Corresponding author:

caio.perecin@usp.br (Caio Perecin)

ncerize@ipt.br (Natalia Cerize)

Published online at http://journal.sapub.org/nn

Copyright () 2016 Scientific \& Academic Publishing. All Rights Reserved formulations coupled with iron oxides [7, 8].

PCL is a biodegradable polyester with good permeability and low toxicity, hence indicated for drug-delivery systems [9]. Poloxamer 188, also known as Pluronic F68, is a three-block copolymer of polyethylene oxide-poly propylene oxide-poly ethylene oxide (PEO-PPO-PEO) employed as a surfactant. Poloxamer has the ability to incorporate to membranes followed by translocation into the cells, being able to affect several cellular functions, such as mitochondrial respiration, ATP synthesis, drug efflux transport, apoptotic signal transduction, and gene expression. As consequence, this copolymer can cause sensitization of multiple drug resistance (MDR) tumors to various anticancer agents [10] and enhance drug transport across blood brain [11] and intestinal barriers [12], thus it is convenient to have it at the surface of theranostics.

There are several means to encapsulate nanoparticles [13] and Nano Spray Drying is an interesting one, although it still hasn't been well explored for this porpouse. This novel technique enables the production of submicron particles from a solution or suspension by exploring a piezoelectric driven vibrating mesh atomizer that creates tiny droplets smaller than in classical spray dryers. The collection of the solid particles is also facilitated through a high-efficiency electrostatic collector [14]. This approach has been mainly 
used to encapsulate drugs [15] and proteins [16] into polymeric particles.

In this work, magnetite nanoparticles were synthesized by coprecipitation method and encapsulated by Nano Spray Drying with PCL and Poloxamer 188. The particles generated were characterized by X-Ray Diffraction (XRD), Fourier transform infrared spectroscopy (FT-IR), Dynamic Light Scattering (DLS), Scanning Electron Microscopy (SEM), Thermogravimetric Analysis (TGA), cytotoxicity assays and magnetization in matters of temperature and external magnetic field.

\section{Materials and Methods}

\subsection{Materials}

Iron (III) chloride hexahydrate $\left(\mathrm{FeCl}_{3} \cdot 6 \mathrm{H}_{2} \mathrm{O}\right)$, Iron (II) chloride hexahydrate $\left(\mathrm{FeCl}_{2} \cdot 4 \mathrm{H}_{2} \mathrm{O}\right)$, Polycaprolactone (PCL, MW 14000) and Kolliphor® P188 (Poloxamer 188, MW 8350 ) were purchased from Sigma-Aldrich. Ammonium hydroxide solution $\left(\mathrm{NH}_{3}\right) 25 \%$ is of Merck.

\subsection{Synthesis of Magnetite Nanoparticles}

Magnetite nanoparticles were synthesized by coprecipitation method. $\mathrm{FeCl}_{2} \cdot 4 \mathrm{H}_{2} \mathrm{O} \quad(5.97 \mathrm{~g})$ and $\mathrm{FeCl}_{3} .6 \mathrm{H}_{2} \mathrm{O}(12.16 \mathrm{~g})$ were solubilized in water $(200 \mathrm{ml})$ and $\mathrm{NH}_{3}(50 \mathrm{ml})$ was added dropwise, under constant stirring, sonication and nitrogen gas purging to the solution, during 45 minutes. The precipitate was centrifuged and dried at $40^{\circ} \mathrm{C}$. The generated powder was named "Mag".

\subsection{Encapsulation by Nano Spray Drying}

Encapsulation process was performed in a Nano Spray Dryer equipment, designed by BUCHI. Magnetite $(0.2 \mathrm{~g})$ was dispersed with PCL $(1 \mathrm{~g})$ and Poloxamer $188(1 \mathrm{~g})$ in acetone $(100 \mathrm{ml})$ under ultrasonication. The suspension was filtered to eliminate magnetite agglomerates and after that, it was fed to the Nano Spray Dryer under constant stirring. Spray membrane with $5.5 \mu \mathrm{m}$ holes, inlet temperature of $65^{\circ} \mathrm{C}$ and $\mathrm{O}_{2}$ concentration below $4 \%$ (required for organic solvents). The resulting powder was named "Mag/PCL/Pol".

\subsection{Characterization}

The characterization of samples was performed as follows: XRD by Shimadzu XRD-6000 diffractometer, source of $\mathrm{Cu}$, $2 \theta$ from $10^{\circ}$ to $80^{\circ}, 1 \% \mathrm{~min}$. FT-IR by Shimadzu IRAffinity- 1 , from 400 to $4000 \mathrm{~cm}^{-1}$, with $\mathrm{KBr}$ pellets. TGA by Mettler Toledo TGA/DSC 1 , from $25^{\circ}$ to $1000^{\circ}$, under $\mathrm{N}_{2}$ flow of 80 $\mathrm{mL} / \mathrm{min}$. DLS by Zetasizer Nano ZS (Malvern Instruments); nanoparticles were dispersed in water (and Tween 80, for Mag/PCL/Plu). Microscopy of samples' powders by high resolution microscope (SEM-FEG) Quanta 3D, by FEI. Magnetic measurements by Cryogenic S600 SQUID Magnetometer. For Zero-field-cooling (ZFC), samples were cooled to $2 \mathrm{~K}$ without external magnetic field $(\mathrm{H})$, then an $\mathrm{H}$ of 150 Oe was applied and magnetization (M) was registered during heating of the sample to $300 \mathrm{~K}$. For Field-cooling (FC), samples were cooled to $2 \mathrm{~K}$ under $\mathrm{H}$ of $150 \mathrm{Oe}$, and $\mathrm{M}$ was measured during the heating, under the same $\mathrm{H}$. For $\mathrm{M}$ vs. $\mathrm{H}$ measurements, particles were kept at $2 \mathrm{~K}$ and at $300 \mathrm{~K}$, while $\mathrm{H}$ varied from -65 to $+65 \mathrm{kOe}$. Cytotoxicity evaluation was assessed through neutral red uptake assay according ISO 10993-5 [17], for mouse fibroblasts cells NCTC-929, tumoral HeLa and HepG2 cells, under 5, 2.5, 1.3, 0.6, 0.3, 0.2 and $0.1 \mathrm{mg} / \mathrm{mL}$ concentrations of particles.

\section{Results and Discussions}

The synthesis of magnetite resulted in a black powder (Mag) and the encapsulation process formed a brownish powder (Mag/PCL/Pol). Chacaracterizations of both powders are described below.

DLS experiment was performed to determinate the hydrodynamic size of the particles. Analysis by number indicated that Mag has a mean diameter of $49 \mathrm{~nm}$ (standard deviation of $22 \mathrm{~nm}$ ) with unimodal distribution (Figure 1). For Mag/PCL/Pol, the size distribution's main peak is of 600 $\mathrm{nm}$ (standard deviation of $62 \mathrm{~nm}$ ), referring to $91 \%$ of the scattered light intensity, while the average size is of $1568 \mathrm{~nm}$ (Figure 2). Small intensities around $10 \mathrm{~nm}$ are probably due to micelles of Tween 80 , used to help dispersate the particles.

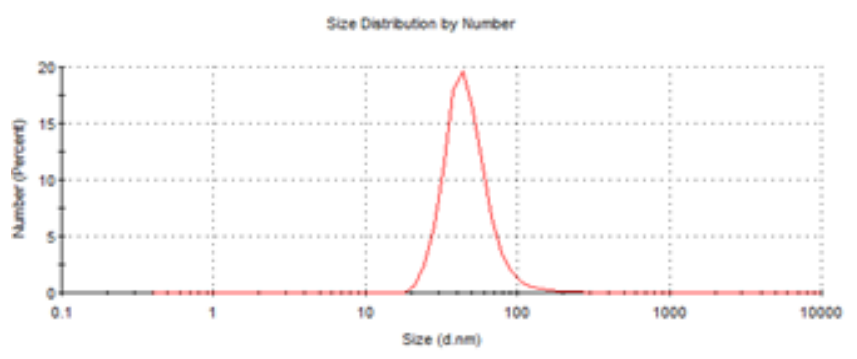

Figure 1. Hydrodynamic size distribution determined by DLS of Mag

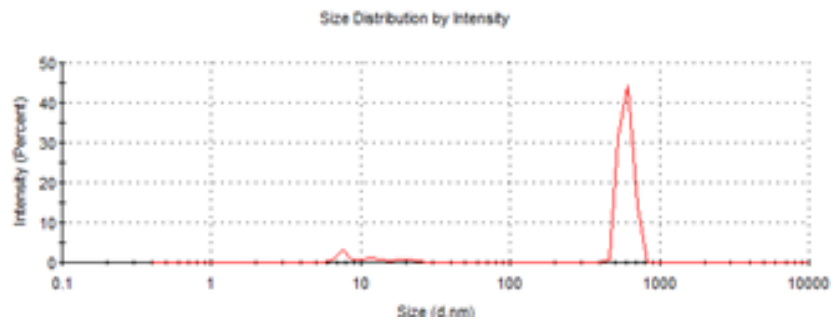

Figure 2. Size distribution determined by DLS of Mag/PCL/Pol

Scanning Electron Microscopy images of samples are shown at Figure 3 and Figure 4. The powder of Mag consists of nanoparticles of around $25 \mathrm{~nm}$, less than what DLS indicated. In water, these nanoparticles form bigger aggregates, which are registered by DLS measures. Mag/PCL/Pol's particles have a smooth surface consisting of polymers, with varied size; Mag's nanoparticles apparently are located in the interior of the particles, since they are not seen isolated. One can picture the particle as a "nanocookie" of a PCL/Poloxamer blend with magnetite nanoparticles embedded in it. 


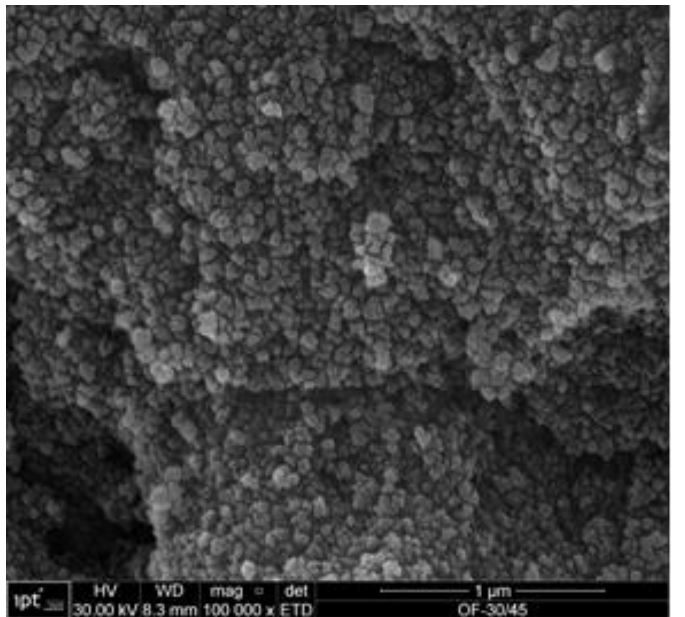

Figure 3. Scanning Electron Microscopy images of Mag. Zoom of $100,000 \mathrm{x}$

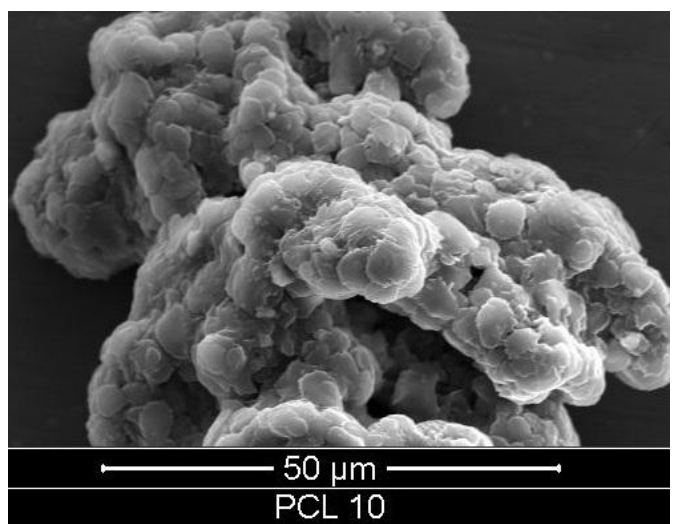

Figure 4. Scanning Electron Microscopy images of Mag/PCL/Pol. Zoom of $2,000 x$

Figure 5 shows the XRD spectra of Mag and Mag/PCL/Pol. Mag has the usual peaks of a magnetite [18].
Mag/PCL/Plu spectra has the peaks known for PCL and Poloxamer (between $19^{\circ}$ and $24^{\circ}$ ) and Mag's peaks in lower intensity. Figure 6 presents the FT-IR spectra of Mag/PCL/Pol, PCL, Poloxamer 188 and Mag. The bands of PCL are evident in Mag/PCL/Pol spectra, while Poloxamer's and Mag's bands have lower intensity. These results confirm that $\mathrm{Mag} / \mathrm{PCL} / \mathrm{Pol}$ is an hybrid material consisting of Mag's nanoparticles entrapped in a matrix of PCL and Poloxamer.

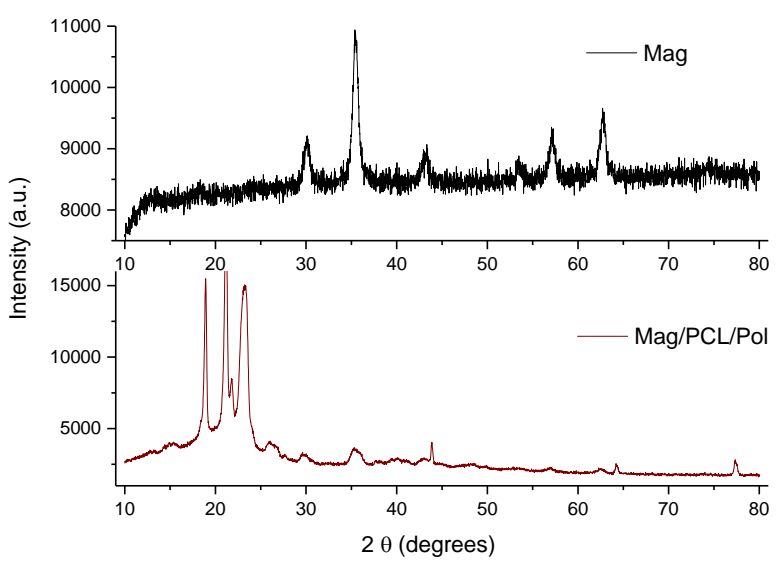

Figure 5. XRD spectra of Mag and Mag/PCL/Pol

In a thermogravimetric analysis up to $1000^{\circ} \mathrm{C}$ at inert atmosphere (weight residues at Table 1), Mag/PCL/Pol lost $96.88 \%$ of its initial weight, related to polymer degradation, and had a residue of $3.12 \%$. PCL and Poloxamer polymers had small residues of $0.12 \%$ and $0.3 \%$, respectively. Mag lost only $3.61 \%$ related to impurities, remaining with $96.39 \%$ of its initial weight, correspondent to magnetite since it is not degraded until $1000^{\circ} \mathrm{C}$. Therefore, the approximately $3 \%$ residue of Mag/PCL/Pol is probably related to magnetite and can be an estimative of Mag's portion in it.

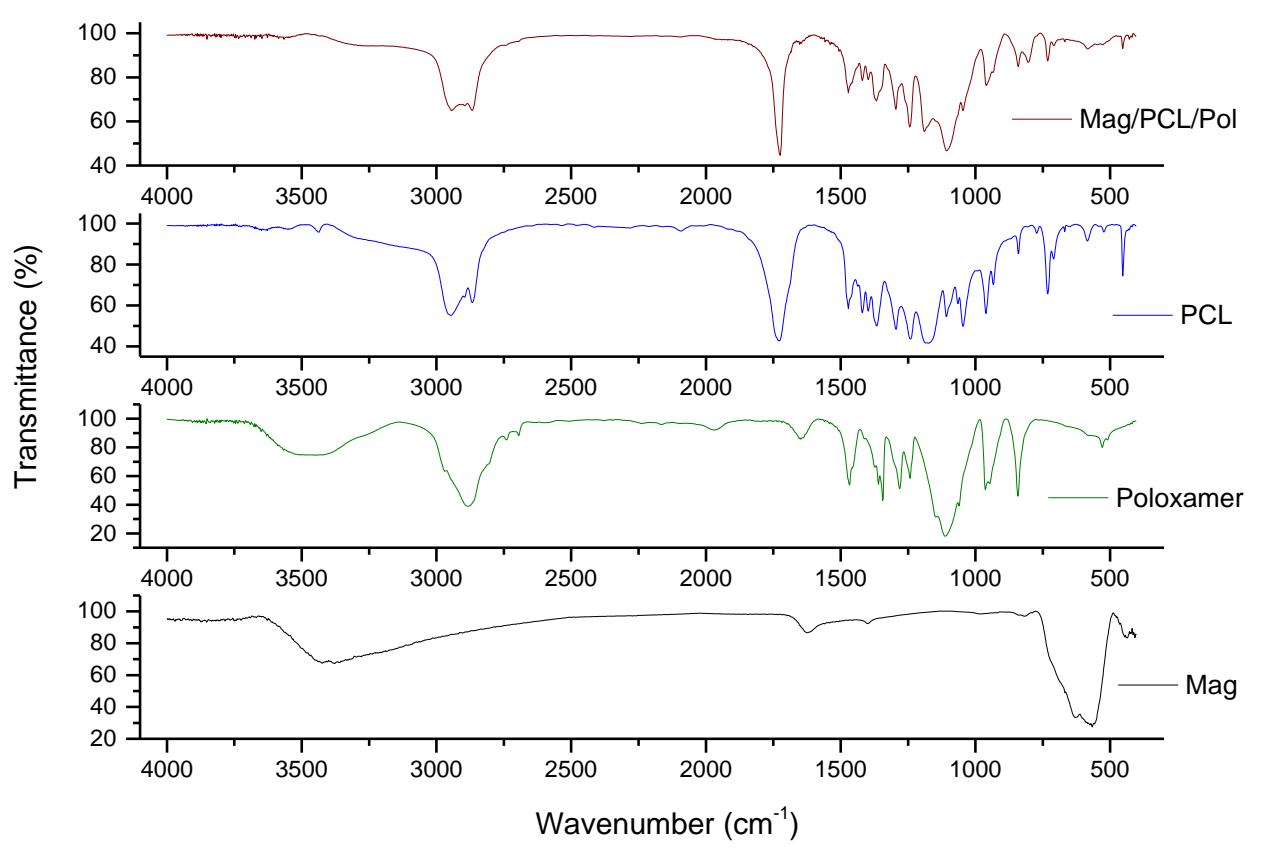

Figure 6. FT-IR spectra of Mag/PCL/Pol, PCL, Poloxamer 188 and Mag 
Table 1. Weight percent residues of thermogravimetric analysis (TGA) up to $1000^{\circ} \mathrm{C}$ with nitrogen flow

\begin{tabular}{|c|c|c|c|c|}
\hline Sample & Mag & PCL & Poloxamer 188 & Mag/PCL/Pol \\
\hline Residue (\%) & 96.39 & 0.12 & 0.3 & 3.12 \\
\hline
\end{tabular}

ZFC and FC curves of Mag and Mag/PCL/Pol, shown in Figure 7 , have similar shapes, only differing in the magnetization intensities, which indicates that after the encapsulation process the magnetite nanoparticles maintained the same magnetic behavior they had before. ZFC curves do not decline, indicating that neither of the particles are formally superparamagnetic up to $300 \mathrm{~K}$, although their coercivities verified in Figure 7 are quite small - around $2 \mathrm{kOe}$ at $2 \mathrm{~K}$ and negligible at $300 \mathrm{~K}$. The magnetic behavior of the samples may be called superparamagnetic-like.

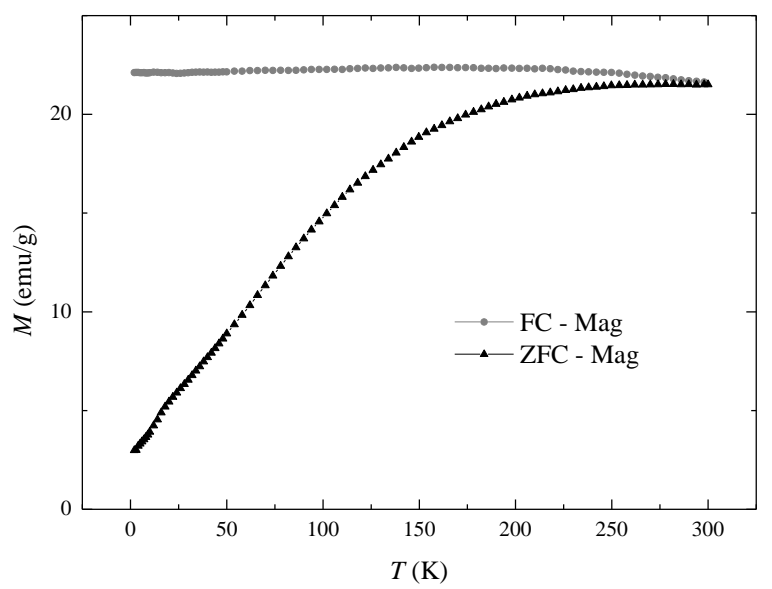

a)

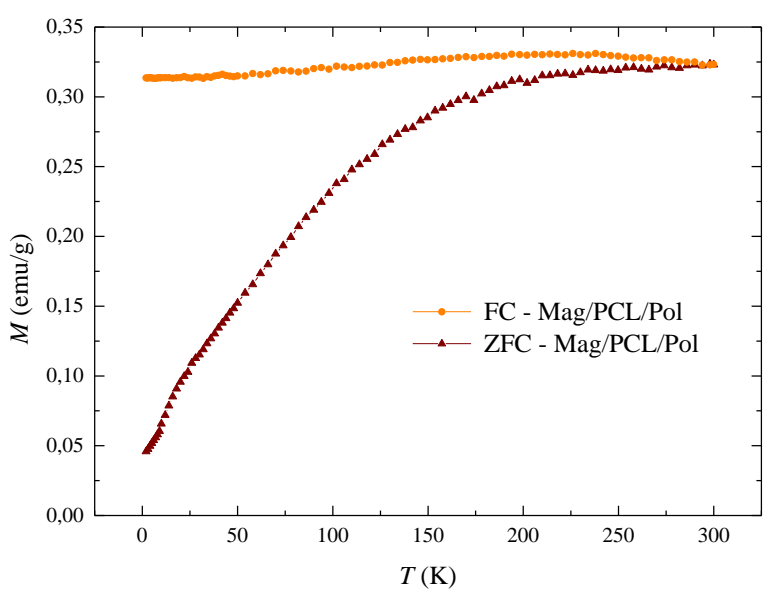

b)

Figure 7. Field-Cooling (FC) and Zero-Field-Cooling (ZFC) graphs of Mag (a) and Mag/PCL/Pol (b)

Magnetization vs. applied magnetic field $\mathrm{H}$ curves at 2 and $300 \mathrm{~K}$ are presented in Figure 8. Magnetic saturation of $\mathrm{Mag} / \mathrm{PCL} / \mathrm{Pol}$ at $1.7 \mathrm{~K}(1.42 \mathrm{emu} / \mathrm{g})$ is higher than at $300 \mathrm{~K}$ $(1.22 \mathrm{emu} / \mathrm{g})$, because in the latter case the thermal energy is able to flip the magnetic moments of the particles, decreasing the number of particles with magnetic moments aligned with the external field applied. Mag curves are similar to $\mathrm{Mag} / \mathrm{PCL} / \mathrm{Pol}$, only differing on saturation $-71.4 \mathrm{emu} / \mathrm{g}$ at $300 \mathrm{~K}$ and 83.4 at $2 \mathrm{~K}$. The saturation value of the encapsulated formulation is equal to $1.7 \%$ of the pure magnetite, which could be another estimation of the quantity of Mag in Mag/PCL/Pol - a little lower than what TGA indicates.

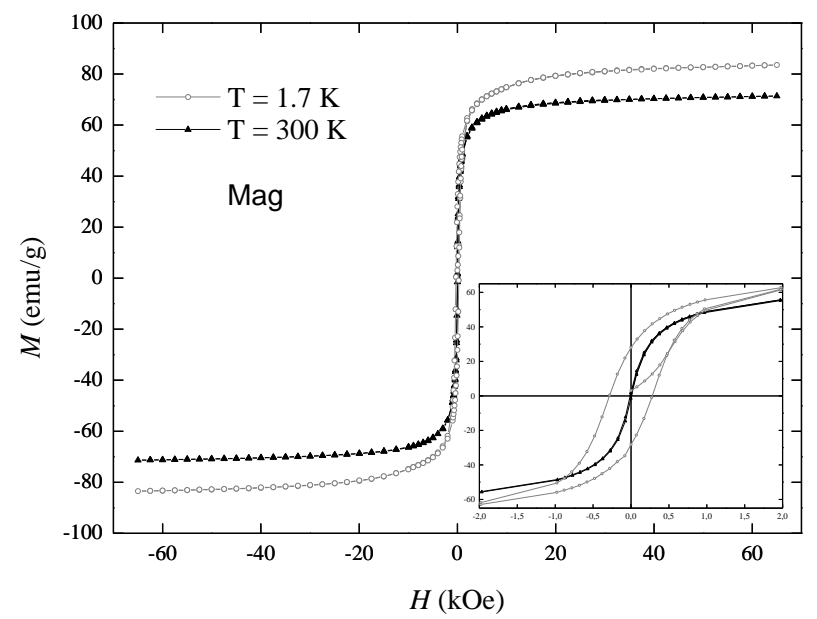

a)

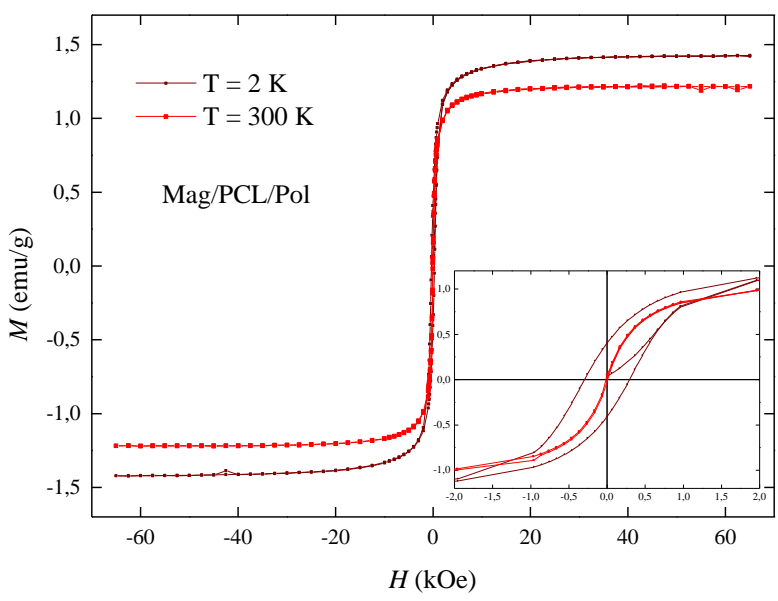

b)

Figure 8. Magnetization vs. external magnetic field $\mathrm{H}$ graphs and detail of coercivity around small fields of Mag (a) and Mag/PCL/Pol (b)

At last, particles' cytotoxicity was evaluated against tumor cells HepG2 and HeLa, as well as to healthy cells NCTC 929. The results for NCTC 929 cells indicate that Mag (Figure 9-a) had minimum effect on its viability, while Mag/PCL/Pol (Figure 9-b) presented cytotoxic effect under high concentrations, with IC 50 superior to $2.5 \mathrm{mg} / \mathrm{mL}$. According to Bracher et al. [19], substances with IC 50 superior than $0.175 \mathrm{mg} / \mathrm{ml}$ are considered nonirritant. Thus, the particles are safe to be tested for biological applications in vivo on concentrations below that of IC 50. No cytotoxicity potential of both particles on HeLa and HepG2 tumoral was observed. In fact, the viability of these cells was superior than control when they were in contact with Mag/PCL/Pol. These results may indicate a preferential 
interaction with tumor cells, which can be explored to address the particles specifically to them.

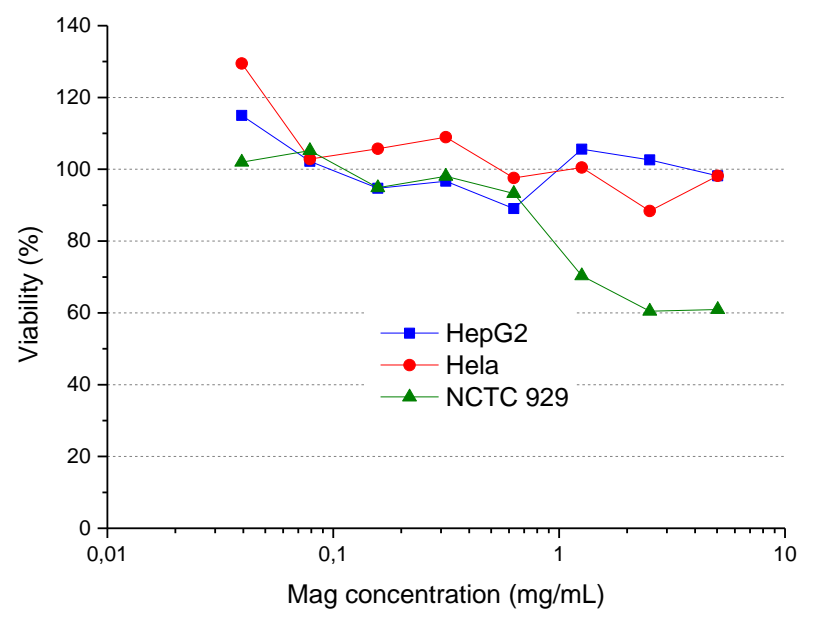

a)

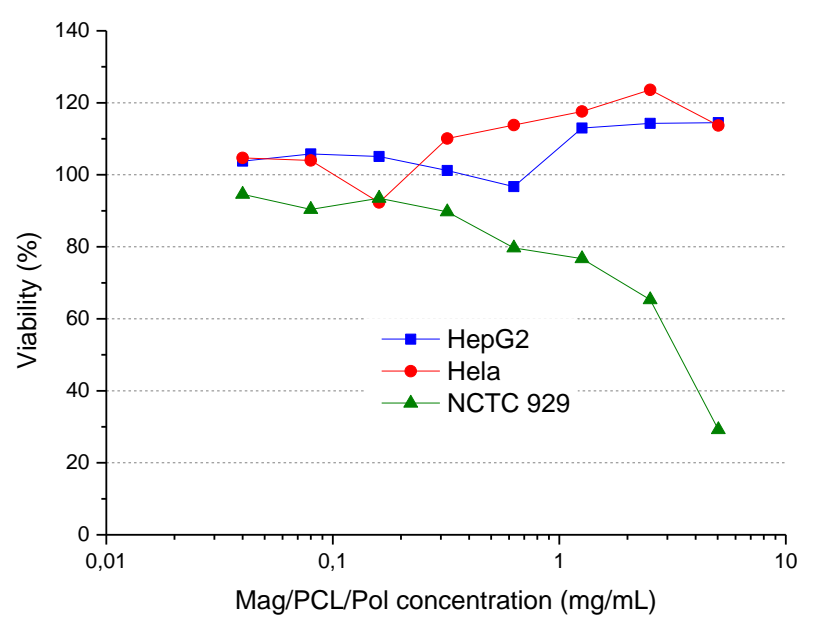

b)

Figure 9. Viability of HeLa, HepG2 and NCTC 929 cells in contact with different concentrations of Mag (a) and Mag/PCL/Pol (b)

\section{Conclusions}

The results indicate that the Nano Spray Drying technique was able to encapsulate magnetite nanoparticles with PCL and Poloxamer 188, generating particles analogous to "nanocookies" of a PCL/Poloxamer blend with magnetite, with a hydrodynamic size of approximately $600 \mathrm{~nm}$. It is expected that the encapsulated formulation, with increase of the magnetite loading, can be used for biological applications, for example, magnetic hyperthermia to treat tumors. Also, this easy proposed process would allow to encapsulate concomitantly other bioactive molecules into the particle by simply mixing them into the suspension before the drying process, thus creating a magnetic platform for drug delivery.

\section{ACKNOWLEDGMENTS}

The authors would like to thank Coordenação de Aperfeiçoamento de Pessoal de Nível Superior (CAPES) and Fundação de Apoio ao Instituto de Pesquisas Tecnológicas (FIPT) for the sponsorship.

\section{REFERENCES}

[1] YOO, D. et al. Theranostic Magnetic Nanoparticles. Accounts of Chemical Research, v. 44, p. 863-874, 2011.

[2] CORCHERO, J. L.; VILLAVERDE, A. Biomedical applications of distally controlled magnetic nanoparticles. Trends in Biotechnology, v. 27, n. 8, p. 468-476, 2009.

[3] PANKHURST, Q. et al. Applications of magnetic nanoparticles in biomedicine. Journal of Physics D: Applied Physics, Bristol, v. 36, n. 13, p. R167-R181, 2003.

[4] COLE, A. J.; YANG, V. C.; DAVID, A. E. Cancer Theranostics: The Rise of Targeted Magnetic Nanoparticles. Trends in Biotechnology, v. 29, n. 7, p. 323-332, 2011.

[5] LU, A.-H.; SALABAS, E. L.; SCHUTH, F. Magnetic Nanoparticles: Synthesis, Protection, Functionalization, and Application. ANGEWANDTE CHEMIE-INTERNATIONAL EDITION, Wenheim, v. 46, n. 8, p. 1222-1244, 2007.

[6] MA, G.; SONG, C. PCL/Poloxamer 188 Blend Microsphere for Paclitaxel Delivery: Influence of Poloxamer 188 on Morphology and Drug Release. Journal of Applied Polymer Science, Hoboken, v. 104, n. 3, p. 1895-1899, 2007.

[7] AHMED, N. et al. Modified double emulsion process as a new route to prepare submicron biodegradable magnetic/polycaprolactone particles for in vivo theranostics. Soft Matter, v. 8, p. 2554-2564, 2012.

[8] LAI, J.-R. et al. Multifunctional doxorubicin/ superparamagnetic iron oxide-encapsulated Pluronic F127 micelles used for chemotherapy/magnetic resonance imaging. Journal of Applied Physics, v. 107, n. 9, p. 09B318-1-3, 2010 .

[9] MA, Y. et al. Nanoparticle formulation of poly(3-caprolactone-co-lactide)-D-a-tocopheryl polyethylene glycol 1000 succinate random copolymer for cervical cancer treatment. POLYMER, Oxon, v. 51, n. 25, p. 5952-5959, 2010.

[10] MINKO, T. et al. Pluronic block copolymers alter apoptotic signal transduction of doxorubicin in drug-resistant cancer cells. Journal of Controlled Release, v. 105, n. 3, p. 269-278, 2005.

[11] BATRAKOVA, E. V. et al. Mechanism of Pluronic Effect on P-Glycoprotein Efflux System in Blood-Brain Barrier: Contributions of Energy Depletion and Membrane Fluidization. Journal of Pharmacology and Experimental Therapeutics, v. 299, n. 2, p. 483-493, 2001.

[12] BATRAKOVA, E. V.; KABANOV, A. V. Pluronic block 
copolymers: Evolution of drug delivery concept from inert nanocarriers to biological response modifiers. Journal of Controlled Release, p. 98-106, 2008.

[13] LADJ, R. et al. Polymer encapsulation of inorganic nanoparticles for biomedical applications. International Journal of Pharmaceutics, v. 458, n. 1, p. 230-241, 2013.

[14] OLIVEIRA, A. M. et al. Nano Spray Drying as an Innovative Technology for Encapsulating Hydrophilic Active Pharmaceutical Ingredients (API). Nanomedicine \& Nanotechnology, v. 4, 2013.

[15] SCHAFROTH, N. et al. Nano and microparticle engineering of water insoluble drugs using a novel spray-drying process. Colloids and Surfaces B: Biointerfaces, v. 90, p. 8-15, 2012.
[16] LEE, S. H. et al. Nano spray drying: A novel method for preparing protein nanoparticles for protein therapy. International Journal of Pharmaceutics, v. 403, n. 1-2, p. 192-200, 2011.

[17] INTERNATIONAL ORGANIZATION FOR STANDARDIZATION. Tests for Cytotoxicity: In Vitro Methods. In: ISO DOCUMENT 10993-5 Biological evaluation of medical devices. [S.1.]: [s.n.], 1992.

[18] CORNELL, R. M.; SCHWERTMANN, U. The Iron Oxides: Structure, Properties, Reactions, Occurences and Uses. 2. ed. [S.1.]: Wiley Online Library, 2004.

[19] BRACHER, M.; FALLER, C.; SPENGLER, J. Comparison of in vitro cell toxicity with in vivo eye irritation. Mol Toxicol, v. 4, p. 561-70, 1988. 